\title{
Phase Behavior of Polystyrene-block-poly(2-vinylpyridine) Copolymers in a Selective Ionic Liquid Solvent
}

\author{
Justin M. Virgili, ${ }^{\dagger \neq}$ Alexander Hexemer,${ }^{\S}$ John A. Pople, ${ }^{\perp}$ Nitash P. Balsara,,$\stackrel{+,+,, l}{ }$ and \\ Rachel A. Segalman*t, $\dagger$ \\ ${ }^{\dagger}$ Department of Chemical Engineering, University of California, Berkeley, California $94720,{ }^{\dagger}$ Materials \\ Sciences and ${ }^{\S}$ Advanced Light Source and $d^{\|}$Energy and Environmental Technologies Divisions, Lawrence \\ Berkeley National Laboratory, Berkeley, California 94720 , and ${ }^{\perp}$ Stanford Synchrotron Radiation Laboratory, \\ Menlo Park, California 94025
}

Received March 5, 2009; Revised Manuscript Received May 18, 2009

\begin{abstract}
The phase behavior of poly(styrene-block-2-vinylpyridine) copolymer solutions in an imidazolium bis(trifluoromethane)sulfonamide ([Im][TFSI]) ionic liquid has been studied using small-angle X-ray scattering (SAXS) and optical transmission characterization. Through scaling analysis of SAXS data, we demonstrate that the [Im][TFSI] ionic liquid behaves as a selective solvent toward one of the blocks. We observe lyotropic and thermotropic phase transitions that correspond qualitatively to the phase behavior observed in block copolymer melts and block copolymer solutions in molecular solvents. In addition, we have studied the thermal properties of block copolymer solutions in the ionic liquid using differential scanning calorimetry and wide-angle X-ray scattering. We observe distinct composition regimes corresponding to the change in the block copolymer's glass transition temperature, $T_{\mathrm{g}}$, with respect to the concentration of polymer in ionic liquid. At high block copolymer concentrations, a "salt-like" regime corresponding to an increase in the block copolymer $T_{\mathrm{g}}$ is observed, while at intermediate block copolymer concentrations, a "solvent-like" regime corresponding to a decrease in the block copolymer $T_{\mathrm{g}}$ is observed. An unusual thermal transition consisting of crystallization and subsequent melting of the ionic liquid is observed at the lowest block copolymer concentration characterized.
\end{abstract}

\section{Introduction}

Ionic liquids are a novel class of solvents composed entirely of ions which exhibit exceptional physiochemical properties, such as nonflammability, negligible vapor pressure, high ionic conductivity, and electrochemical stability. 1 The outstanding electrochemical properties of ionic liquids have led to studies involving their use in lithium battery electrolytes, ${ }^{2,3}$ fuel cells, ${ }^{4-8}$ and dye-sensitized solar cells. ${ }^{9-12}$ While the need for introducing ionic liquids into a solid supporting matrix for these applications has been recognized, ${ }^{13}$ the combination of block copolymers and ionic liquids results in a new class of functional materials with intricate structure on the nanometer scale. ${ }^{14}$ The structure is created by block copolymer self-assembly, while the functionality is obtained by exploiting the properties of ionic liquids. Block copolymer/ionic liquid systems enable the design of materials whose ion-conducting and mechanical properties can be separately optimized.

Effects resulting from the addition of both selective and. nonselective molecular solvents to block copolymers on both the self-assembled nanostructure and the thermodynamic driving forces affecting self-assembly have been extensively investigated using both experiments ${ }^{15-17}$ and theory. ${ }^{18-20}$ At fixed temperature, the addition of solvents to diblock copolymers results in a rich variety of lyotropic phase transitions. ${ }^{15,16}$ The temperature dependence of interactions between the two blocks, and interactions between the blocks and the solvent, lead to an additional set of thermotropic phase transitions. Lai et al.

\footnotetext{
*Corresponding authors. E-mail: nbalsara@berkeley.edu (N.P.B.), segalman@berkeley.edu (R.A.S.).
}

observed temperature-dependent scaling behavior of the characteristic domain spacing in polystyrene-block-poly(isoprene) (SI) copolymer solutions in selective solvents. ${ }^{21}$ This observation was attributed to the temperature dependence of the solvent/ block copolymer segment interaction parameter, leading to changes in solvent partitioning between the polystyrene and poly(isoprene) microphases as temperature was varied. Hanley et al. have shown that thermotropic properties of mixtures of SI copolymers and diethyl phthalate arise from the temperature dependence of solvent selectivity. ${ }^{18}$ Alexandridis et al. have conducted a thorough investigation of the phase behavior of poly(ethylene oxide-block-propylene oxide-block-ethylene oxide) PEO copolymers (Pluronic) in water, a solvent that is selective toward the poly(ethylene oxide) (PEO) block. ${ }^{22}$ One of the observations of Alexandridis et al. was the strong temperature dependence of micelle formation in dilute Pluronic/water mixtures. ${ }^{23}$ The temperature dependence of block copolymer/solvent interactions, however, is not universal across all systems. For example, Hadjuk et al. observed weak temperature dependence of solvent/polymer interactions in concentrated solutions of an asymmetric PEO-block-poly(ethyl ethylene) copolymer in water, ${ }^{24}$ despite strongly thermotropic interactions between PEO and water. ${ }^{25}$ These findings suggest that block copolymer composition and the local structure of water molecules surrounding the PEO segments play an important role in determining the phase behavior of copolymer solutions containing PEO blocks.

Water-containing polyelectrolyte membrancs arc of interest for fuel cell applications, ${ }^{26,27}$ and the incorporation of nanostructure has recently been shown to significantly improve water uptake, while maintaining mechanical stability. ${ }^{28,29}$ Incorporation of ionic liquids into polymer membranes is also of interest 


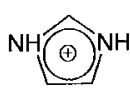<smiles>O=S(=O)(NS(=O)(=O)C(F)(F)F)C(F)(F)F</smiles><smiles>CCC(C)(C)CC(C)C(C)(C)CC(C)c1ccccn1</smiles>

Figure 1. Chemical structure of the imidazolium bis(trifluoromethane) sulfonamide ([Im][TFSI]) ionic liquid and the poly(styrene-block-2vinylpyridine) (S2VP) copolymer.

due to their high conductivities and potential use at elevated temperatures. ${ }^{5,30,31}$ Several approaches toward achieving solid, nanostructured ionic-liquid-containing polymer films have been demonstrated. Ohno et al. synthesized ion conducting polymers with ionic liquid groups tethered to flexible side chains of vinyl-based monomers. ${ }^{32}$ Susan et al. prepared ionic gels through in situ polymerization of poly(methyl methacrylate) (PMMA) in a 1-ethyl-3-methylimidazolium bis(trifluoromethane)sulfonamide ([EMI][TFSI]) ionic liquid. ${ }^{13}$ Matsuoka et al. synthesized a polybase with a coupled phenylene/oxadiazole repeat unit and doped HTFSI into this solid matrix. ${ }^{5}$ Yoshio et al. incorporated an ionic liquid moiety into liquid crystalline molecules that were self-assembled and then photopolymerized into well-defined nanostructures. ${ }^{33} \mathrm{He}$ et al. produced ABA triblock copolymer gels by codissolving small amounts of block copolymer and ionic liquid with a cosolvent and subsequent removal of the solvent. ${ }^{34}$ These ionic gels exhibit conductivities comparable to the neat ionic liquid and possess significant mechanical strength. In work closely related to the present study, Simone and Lodge studied the lyotropic phase behavior of poly(butadiene)-block-PEO (PB-block-PEO) copolymer solutions in two imidazolium ionic liquids ([EMI][TFSI] and 1-butyl-3-methylimidazolium hexafluorophosphate ([BMI]$\left.\left[\mathrm{PF}_{6}\right]\right)$ ) and demonstrated that the ionic liquids behave essentially as a selective solvent. ${ }^{14}$

The addition of charged species affects the thermal properties of both homopolymers and block copolymers. The addition of salt to PEO increases the glass transition temperature $\left(T_{\mathrm{g}}\right)$ of the polymer due to physical cross-linking of the polymer chains. ${ }^{35}$ This effect has also been observed in samples comprised of a block copolymer and salt. ${ }^{36}$ In PMMA ionic gels containing an [EMI][TFSI] ionic liquid, Susan et al. observed a monotonic decrease in the $T_{\mathrm{g}}$ of PMMA as the concentration of ionic liquid was increased, suggesting a solvent-like plasticizing effect of the ionic liquid. ${ }^{13}$ In PEO ionic gels containing a related imidazolium ionic liquid, Klingshirn et al. observed values of the $T_{\mathrm{g}}$ and the crystallization and melting temperatures $\left(T_{\mathrm{c}}\right.$ and $T_{\mathrm{m}}$, respectively) of the ionic liquid within the gel that were identical to that of the pure ionic liquid, leading to the conclusion that the bulk ionic liquid existed in a free, unbound environment within the PEO gel. ${ }^{37}$ These reports suggest that the specific chemistries of the polymer/ionic liquid along with the ionic gel structure play, a critical role in affecting the thermal properties of the composite material.

In this study, we report on the thermotropic and lyotropic phase behavior of a poly(styrene-block-2-vinylpyridine) (S2VP) copolymer in an imidazolium bis(trifluoromethane)sulfonamide ([Im][TFSI]) ionic liquid (Figure 1). We expect the ionic liquid to associate preferentially with the poly(2-vinylpyridine) block. This system was chosen because the imidazolium cation can complex with $\mathrm{H}^{+}$in the absence of water to provide a nonhydrated proton-conducting medium. The S2VP copolymer in [Im][TFSI] ionic liquid thus serves as a model system for a nonhydrated proton exchange fuel cell membrane.

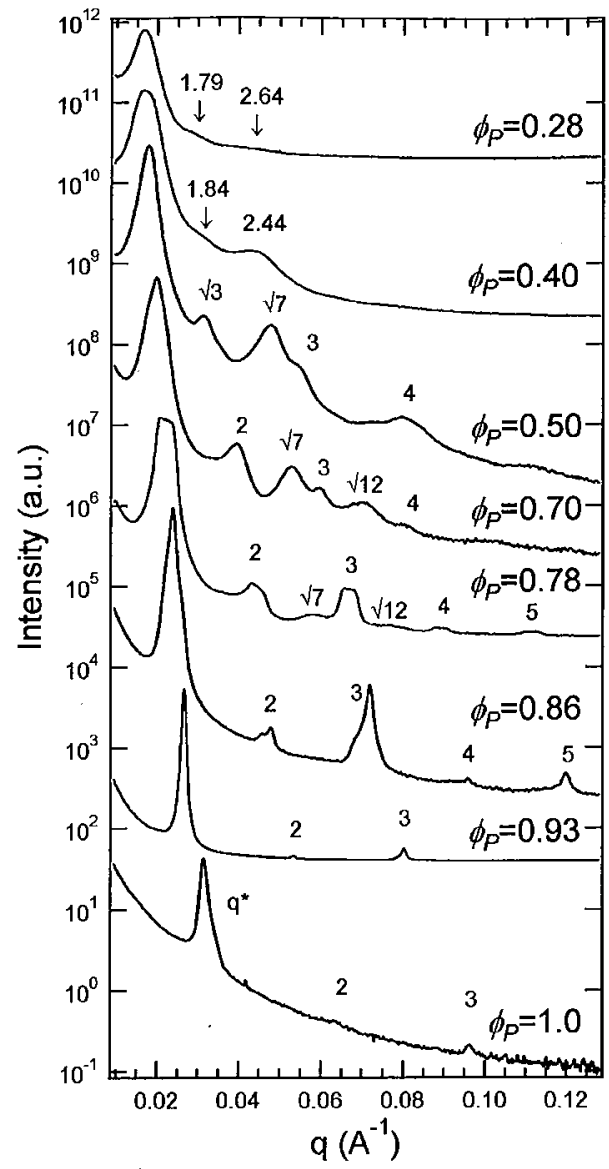

Figure 2. SAXS intensity profiles (offset for clarity) of $\phi_{\mathrm{P}}=0.28$ to $\phi_{\mathrm{P}}=$ $1.0 \mathrm{~S} 2 \mathrm{VP}(13-15)$ copolymer in [Im][TFSI]. In all cases, the peak labels correspond to the $q / q^{*}$ for scattering peaks of a particular composition.

\section{Experimental Section}

Polymer Synthesis and Characterization. A poly(styreneblock-2-vinylpyridine) copolymer and poly(2-vinylpyridine) (P2VP) homopolymer were synthesized via anionic polymerization using standard methods. ${ }^{38}$ The molecular weight of the polystyrene (PS) hompolymer was determined using gel permeation chromatography (GPC), and the total molecular weight of the block copolymer was determined via ${ }^{1} \mathrm{H}$ NMR (Bruker AVB-300). The molecular weight of the P2VP homopolymer was determined using ${ }^{1} \mathrm{H}$ NMR end-group analysis. The polydispersity of each polymer was assessed using GPC. The poly(styreneblock-2-vinylpyridine) copolymer is designated S2VP(13-15), where the numbers in parentheses refer to the number-averaged molecular weights in $\mathrm{kg} / \mathrm{mol}$ of the PS and P2VP blocks, respectively. The P2VP homopolymer is designated P2VP(20), where the number in parentheses refers to the number-averaged molecular weight in $\mathrm{kg} / \mathrm{mol}$. The measured polydispersity of S2VP $(13-15)$ was 1.10 , while the that of $P 2 V P(20)$ was 1.12 .

Ionic Liquid Purification. Imidazole ( $\geq 95 \%$ ) and bis(trifluoromethane)sulfonamide (HTFSI, $\geq 95 \%$ ) were purchased from Sigma-Aldrich and purified by sublimation under vacuum. Differential scanning calorimetry (DSC) and ${ }^{1} \mathrm{H}$ NMR were used to assess the purity of the two starting materials. Purified imidazole and HTFSI were combined in equimolar quantities in a glovebox, sealed, and heated in an oven outside the glovebox to $100{ }^{\circ} \mathrm{C}$ for $2-3 \mathrm{~h}$ to prepare the ionic liquid [Im][TFSI]. The composition of the ionic liquid was confirmed by comparing the measured melting point of the compound, using DSC, with literature. $^{4}$ 


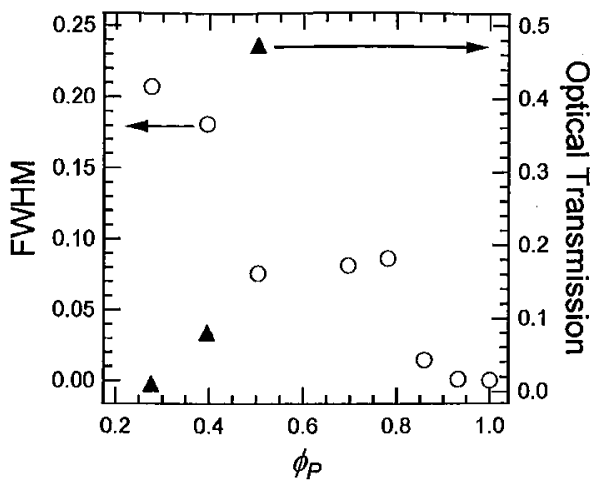

Figure 3. Fwhm of the SAXS primary scattering peak (left axis, O) and optical transmission coefficient (right axis, $\mathbf{\Lambda}$ ) plotted as a function of block copolymer volume fraction, $\phi_{\mathrm{P}}$, at $145 \pm 5^{\circ} \mathrm{C}$.

$\mathrm{X}$-ray Scattering Sample Preparation and Methods. Dichloromethane was degassed using three freeze-pump-thaw cycles, stirred over $\mathrm{CaH}_{2}$ overnight, then distilled into a collection flask, brought into a glovebox, and stored on molecular sieves. Predetermined quantities of [Im][TFSI] and S2VP(13-15) were weighed into glass vials, and ca. $5 \mathrm{wt} \%$ solutions were prepared using dichloromethane in the glovebox. Solutions were stirred overnight. Samples were cast into sample cells with an aluminum spacer sealed onto a Kapton window on one side in the glovebox. The polymer/ionic liquid solution was put into the sample cell one drop at a time. Solvent was allowed to evaporate before addition of the next drop until a ca. $1 \mathrm{~mm}$ solid sample was obtained in the sample cell. Samples were heated to $60^{\circ} \mathrm{C}$ (above the boiling point of dichloromethane) in the glovebox for ca. $18 \mathrm{~h}$ to remove remaining solvent. A second Kapton window was glued to seal the samples, which were stored with desiccant when outside the glovebox to reduce the chance of water contamination. Samples are designated by the value of the estimated polymer volume fraction (for both S2VP and $\mathrm{P} 2 \mathrm{VP}$ solutions), $\phi_{\mathrm{P}}$, assuming ideal mixing. The density of [Im][TFSI] was estimated to be $1.67 \mathrm{~g} / \mathrm{cm}^{3}$ from scattering length density fits of small-angle neutron scattering (SANS) intensity profiles, ${ }^{39}$ and the densities of PS and P2VP were taken to be 1.15 and $1.05 \mathrm{~g} / \mathrm{cm}^{3}$, respectively.

Small-angle X-ray scattering (SAXS) and wide-angle X-ray scattering (WAXS) were performed on beamline 7.3.3 of the Advanced Light Source (ALS), and SAXS was performed on beamline 1-4 of the Stanford Synchrotron Radiation Laboratory (SSRL). At the ALS, the beamline was configured with an $\mathrm{X}$-ray wavelength of $1.240 \AA$ and focused to a 50 by $300 \mu \mathrm{m}$ spot. Full two-dimensional scattering patterns were collected on an ADSC CCD detector with an active area of 188 by $188 \mathrm{~mm}$. The scattering patterns were radially averaged, and the scattering intensity was corrected with the postion chamber intensity using Nika version 1.18. At SSRL, the beamline was configured with an X-ray wavelength $\lambda=1.488 \AA$ and focused to a $0.5 \mathrm{~mm}$ diameter spot. A single quadrant of a two-dimensional scattering pattern was collected on a CCD detector with an active area of 25.4 by $25.4 \mathrm{~mm}$. The scattering patterns were radially: averaged and corrected for detector null signal, dark current, and empty cell scattering.

Optical Transmission Sample Preparation and Methods. Samples were prepared between two quartz windows with a $0.5 \mathrm{~mm}$ Teflon spacer. Samples were solvent cast from dichloromethane solutions in a manner similar to X-ray scattering sample preparation. All samples were prepared and sealed within a glovebox to minimize water exposure. Optical transmission measurements were performed on a home-built instrument as previously described ${ }^{40}$ Samples were heated to $145^{\circ} \mathrm{C}$, annealed for $1 \mathrm{~h}$, and then cooled to room temperature. This process was repeated twice for each sample. We report values of the transmitted

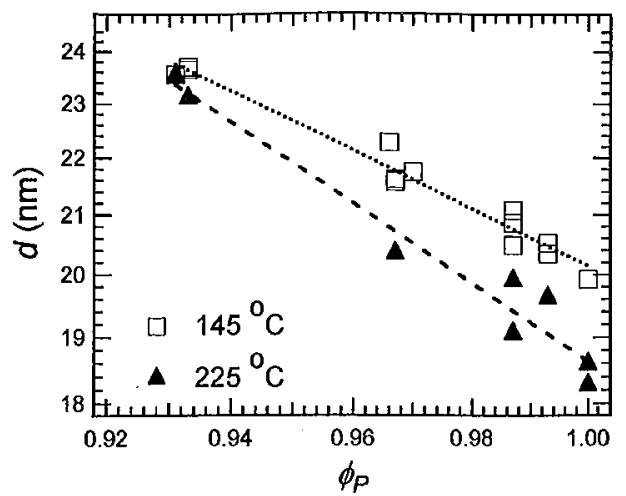

Figure 4. Domain spacing, $d$, versus block copolymer volume fraction, $\phi_{\mathrm{P}}$, determined from SAXS data at $145^{\circ} \mathrm{C}(\square)$ and $225^{\circ} \mathrm{C}(\boldsymbol{\Lambda})$. These plots are used to assess the ionic liquid's solvent selectivity for the S2VP $(13-15)$ copolymer, using a power law fit, $d \sim \phi_{\mathrm{P}}{ }^{\alpha}$, to obtain $\alpha$. At $145^{\circ} \mathrm{C}, \alpha=-2.31$, and at $225^{\circ} \mathrm{C}, \alpha=-3.16$

intensity of a HeNe laser beam $(\lambda=632.8 \mathrm{~nm})$ normalized by that of the incident beam.

Differential Scanning Calorimetry Sample Preparation and Methods. Differential scanning calorimetry (DSC) was performed on a TA Instruments DSC 2920. Samples were solution cast in a glovebox into aluminum DSC pans from the same solutions used to prepare X-ray scattering samples. The samples were heated to $60^{\circ} \mathrm{C}$ in the glovebox for ca. $18 \mathrm{~h}$ to remove remaining solvent. The samples were then crimped within the glovebox using hermetically sealed pans and placed inside a container with desiccant for transfer to the DSC. Indium and dodecane were used as calibration standards for the DSC. Samples underwent three heating and cooling cycles and glass, crystallization, or melting transitions were recorded upon the second heating.

Thermal Gravimetric Analysis Sample Preparation and Methods. Thermal gravimetric analysis (TGA) was performed on a TA Instruments TGA 2950. Samples were solution cast under the same conditions used for DSC sample preparation into open platinum pans, and dichloromethane was removed in a similar manner. Samples were heated at $5{ }^{\circ} \mathrm{C} / \mathrm{min}$ from 30 to $450^{\circ} \mathrm{C}$ under a nitrogen atmosphere.

\section{Results and Discussion}

Representative SAXS profiles from varying concentrations of S2VP(13-15) in the [Im][TFSI] ionic liquid are shown in Figure 2. All of the scattering profiles were recorded at $145^{\circ} \mathrm{C}$, well above the glass transition temperature of the neat copolymer. The neat copolymer exhibits a lamellar morphology with peaks at $q=q^{*}$, $2 q^{*}$, and $3 q^{*}$, where $q=(4 \pi / \lambda) \sin (\theta / 2), \theta$ is the scattering angle, and $q^{*}$ is the value of $q$ at the primary scattering peak. The center-to-center distance between adjacent PS lamellae, $d=2 \pi / q^{*}$, is $19.9 \mathrm{~nm}$, in the case of the neat copolymer. A qualitatively similar lamellar phase with $d=23.6 \mathrm{~nm}$ is obtained in the $\phi_{\mathrm{P}}=0.93$ sample. The large change in the domain spacing upon addition of a small amount of ionic liquid is noteworthy. This expansion is also seen in the $\phi_{\mathrm{P}}=0.86$ sample, which exhibits a lamellar morphology. There are, however, significant differences when one compares the neat block copolymer (and the $\phi_{\mathrm{P}}=0.93$ sample) to the $\phi_{\mathrm{P}}=0.86$ sample. The $\phi_{\mathrm{p}}=0.86$ sample shows peaks that are significantly broader compared to the neat S2VP(13-15) copolymer. The peak at $q=2 q^{*}$ is distinctly bimodal. These facts suggest the existence of two populations of lamellae with $d=26.2$ and $27.5 \mathrm{~nm}$. Roughly $55 \%$ of the higher order peak at $2 q^{*}$ and $86 \%$ at $3 q^{*}$ can be attributed to lamellae with $d=26.2 \mathrm{~nm}$. We propose that this indicates the presence of two coexisting phases with unequal amounts of ionic liquid. 

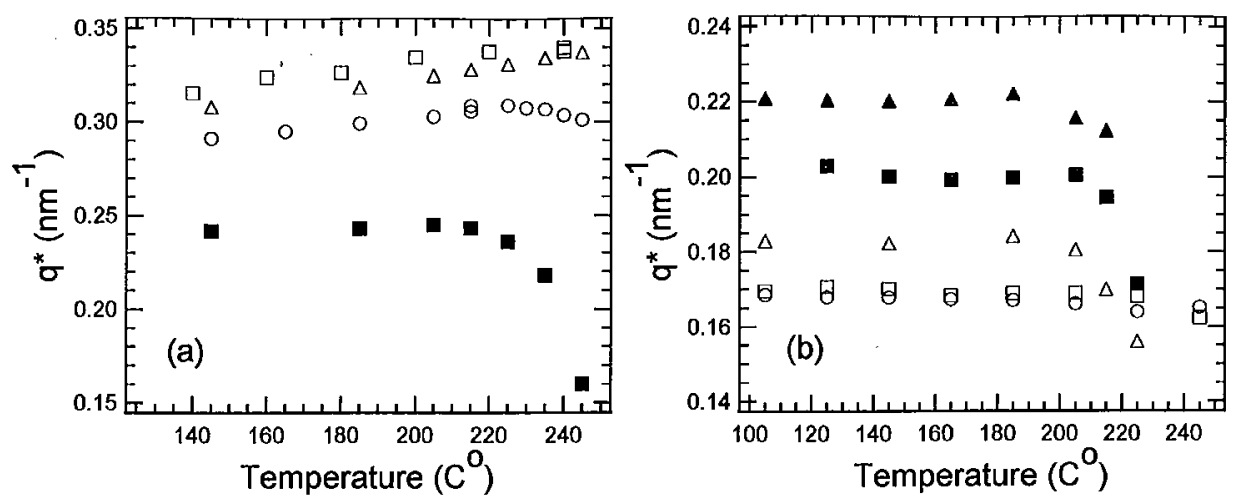

Figure 5. Primary SAXS peak position of S2VP/[Im][TFSI] mixtures, $q^{*}$, plotted as a function of temperature for (a) $\phi_{\mathrm{P}}=1.0$ ( $\square$, neat copolymer), $\phi_{\mathrm{P}}=0.99(\triangle), \phi_{\mathrm{P}}=0.97(\mathrm{O})$, and $\phi_{\mathrm{P}}=0.86(\mathbb{\square})$ and $(\mathrm{b}) \phi_{\mathrm{P}}=0.78(\Delta), \phi_{\mathrm{P}}=0.70(\mathbb{\square}), \phi_{\mathrm{P}}=0.50(\triangle), \phi_{\mathrm{P}}=0.40(\square)$, and $\phi_{\mathrm{P}}=0.28(\mathrm{O})$.
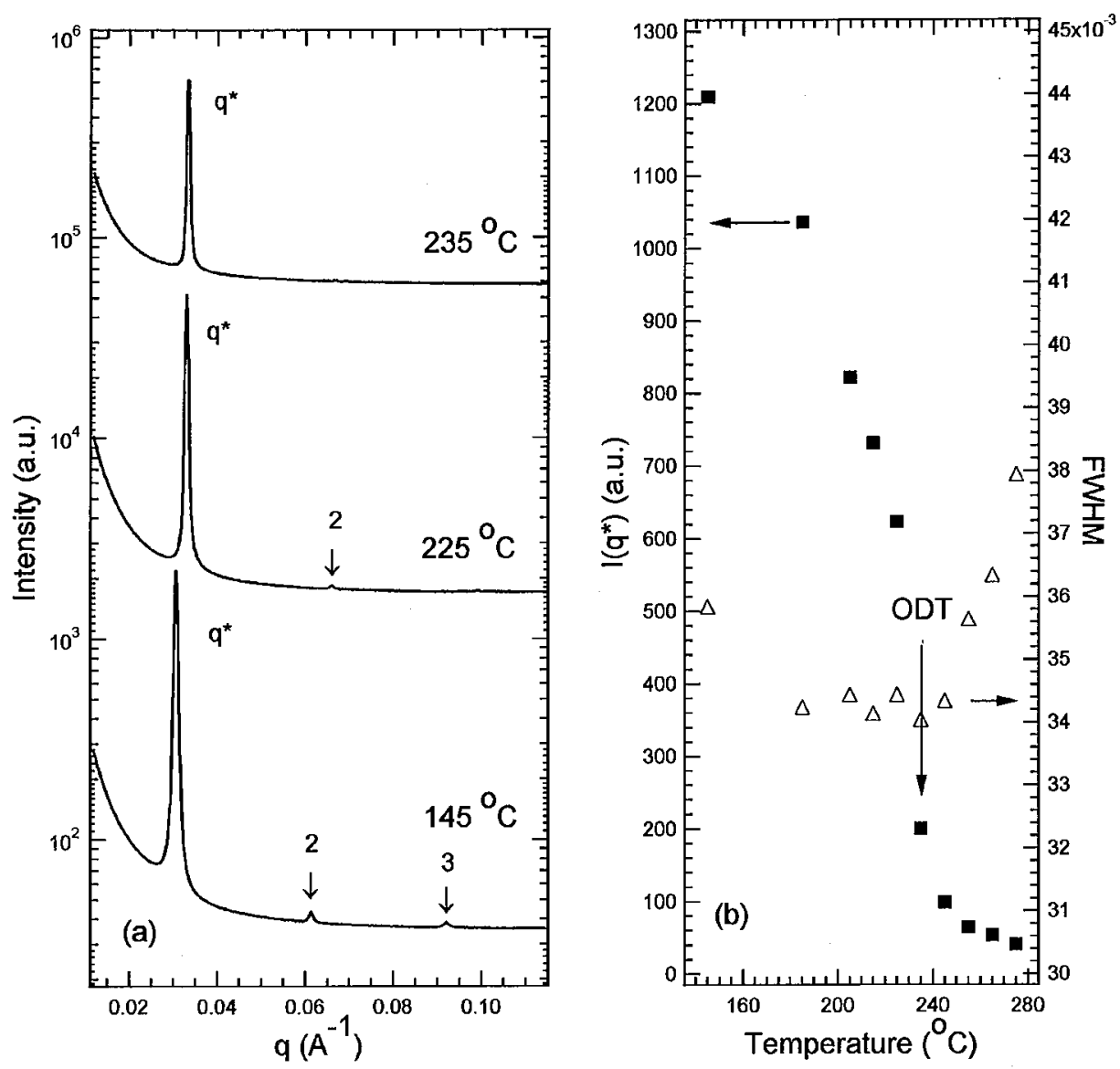

Figure 6. (a) SAXS intensity profiles (offset for clarity) of $\phi_{\mathrm{P}}=0.99 \mathrm{~S} 2 \mathrm{VP}(13-15)$ in [Im][TFSI] at varying temperatures. In all cases, the peak labels correspond to the $q / q^{*}$ for scattering peaks. (b) Plot of $I\left(q^{*}\right)$ (denoted $\sigma$ ) and fwhm (denoted $\triangle$ ) versus temperature $\left({ }^{\circ} \mathrm{C}\right.$ ). The ODT is identified as the point at $235 \pm 10^{\circ} \mathrm{C}$ (vertical arrow).

As the concentration of S2VP copolymer is decreased to $\phi_{\mathrm{P}}=0.78$, the primary scattering peak becomes bimodal. The locations of the higher order peaks indicate the coexistence of lamellar and hexagonally packed cylindrical microstructures with $d=26.9$ and $28.7 \mathrm{~nm}$, respectively. For the cylindrical phase, $d$ represents the spacing between adjacent 110 scattering planes. The presence of higher order scattering peaks at $\sqrt{ } 7 q^{*}$ and $\sqrt{ } 12 q^{*}$ indicates regions of hexagonally packed cylinders within the sample, while the broadness of the $2 q^{*}$ and $3 q^{*}$ peaks is attributed to the distinct characteristic length scales of lamellae and cylinders. The absence of a peak at $\sqrt{3} q^{*}$ is due to a minimum in the form factor of scattering from cylinders with a $10.5 \mathrm{~nm}$ radius. ${ }^{41}$ The radius was determined using the composition of the sample and assuming that the ionic liquid resides exclusively in the P2VP microphase. It appears that the larger lamellae seen in the $\phi_{\mathrm{P}}=0.86$ sample give rise to the hexagonal phase at $\phi_{\mathrm{P}}=0.78$. The coexistence of microstructures persists after a long $(24 \mathrm{~h})$ preanneal at $145^{\circ} \mathrm{C}$ prior to SAXS characterization and also after annealing the sample at $145^{\circ} \mathrm{C}$ for $30 \mathrm{~min}$ on the SAXS beamline. In general, we find the microphase-separated structures observed in S2VP (13-15) copolymer/[Im][TFSI] solutions to be stable over long 

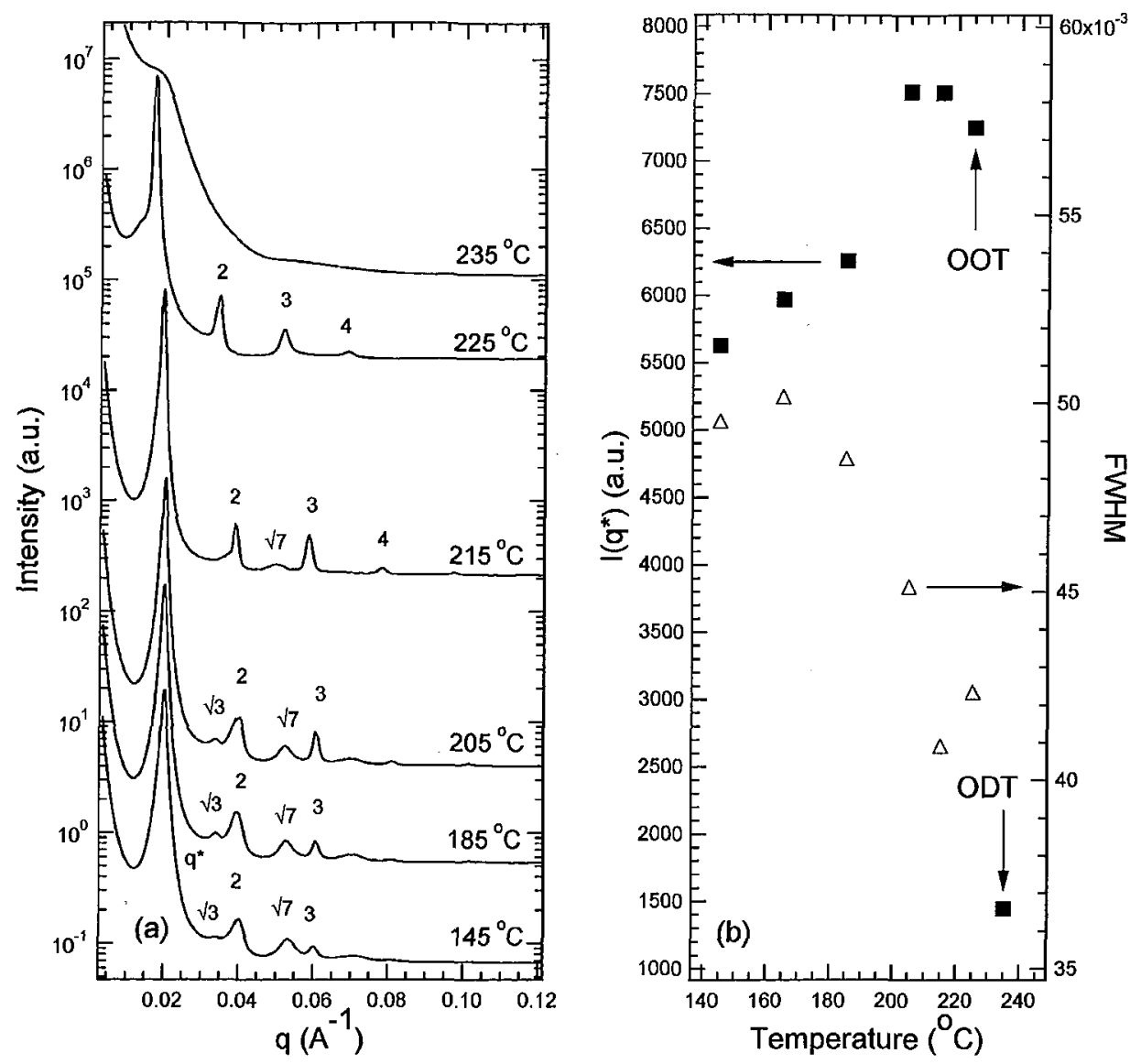

Figure 7. (a) SAXS intensity profiles (offset for clarity) of $\phi_{\mathrm{P}}=0.70 \mathrm{~S} 2 \mathrm{VP}(13-15)$ in $[\mathrm{Im}][\mathrm{TFSI}]$ at varying temperatures. In all cases, the peak labels correspond to the $q / q^{*}$ for scattering peaks. (b) Plot of $I\left(q^{*}\right)$ (denoted $\boldsymbol{B}$ ) and fwhm (denoted $\triangle$ ) versus temperature $\left({ }^{\circ} \mathrm{C}\right.$ ). The OOT and ODT are identified at $225 \pm 10$ and $235 \pm 10^{\circ} \mathrm{C}$, respectively (vertical arrows).

periods of time. Samples stored 1-2 months at room temperature in the glovebox exhibit the same microphase-separated structure and thermodynamic transitions as samples prepared immediately prior to SAXS experiments. As the concentration of the S2VP $(13-15)$ copolymer is further reduced to $\phi_{P}=0.70$, the SAXS profile reveals a single hexagonally packed cylinder phase (Figure 2). The scattering intensity of the $\sqrt{ } 7 q^{*}$ and $\sqrt{ } 12 q^{*}$ peaks is observed to increase dramatically compared to the $\phi_{\mathrm{P}}=$ 0.78 sample, while the scattering intensity of the $3 q^{*}$ and $4 q^{*}$ scattering peaks decreases.

The data obtained from the $\phi_{\mathrm{P}}=1.0$ to $\phi_{\mathrm{P}}=0.70$ samples in Figure 2 establishes a lamellae-to-hexagonally packed cylinder lyotropic phase transition upon the addition of ionic liquid. It is important to note that the Gibbs phase rule requires a coexistence window between two single phase regions in any binary mixture. This coexistence is clearly seen in data from the $\phi_{\mathrm{P}}=0.86$ and $\phi_{\mathrm{P}}=0.78$ samples in Figure 2. Since the coexistence window must contain the two single phases that lie on either side of the window, ${ }^{42}$ we conclude that the $\phi_{\mathbf{P}}=$ 0.78 sample is at equilibrium while the $\phi_{\mathrm{P}}=0.86$ sample is not. We propose that equilibration at $\phi_{\mathrm{P}}=0.86$ is not possible within our experimental window due to small quench depth. Hexagonally perforated lamellae have been determined to be nonequilibrium phases in bulk diblock copolymer systems, ${ }^{43}$ as well as studies of block copolymers in selective molecular solvents, ${ }^{44}$ and do not appear in the present system.

At a composition of $\phi_{\mathrm{P}}=0.50$, we observe the emergence of the $\sqrt{ } 3 q^{*}$ scattering peak, along with the presence of $\sqrt{ } 7 q^{*}, 3 q^{*}$, and
$4 q^{*}$ higher order scattering peaks (Figure 2). The $2 q^{*}$ scattering peak is not observed, due to a minimum in the form factor of scattering from cylinders with a $10.2 \mathrm{~nm}$ radius. Further reduction of the block copolymer concentration to $\phi_{\mathrm{P}}=$ 0.40 results in increased broadening of the primary scattering peak and a decrease in the scattering intensity. A further decrease in scattering intensity and broadening of the main peak is seen in the $\phi_{\mathrm{P}}=0.28$ sample (Figure 2). The scattering profile from these two samples is similar to those found from micellar phases without long-range order. ${ }^{14,18,45} \mathrm{~A}$ plot of the full width at half-maximum (fwhm) of the primary scattering peak at $145^{\circ} \mathrm{C}$ as a function of block copolymer concentration (Figure 3 ) shows three regimes. The smallest values of fwhm are obtained in the lamellar samples, intermediate values are obtained in the coexistence window and the cylindrical samples, and large values are obtained in the micellar samples. The optical transmission coefficient of the S2VP(13-15) copolymer in [Im][TFSI] solutions at $145^{\circ} \mathrm{C}$ shows a dramatic decrease as the concentration of block copolymer is reduced from $\phi_{\mathrm{P}}=0.50$ to $\phi_{\mathrm{P}}=$ 0.40 and continues to decrease for the $\phi_{\mathrm{P}}=0.28$ sample (Figure 3). Single-phase, anisotropic block copolymers (lamellar and cylindrical phases) are generally transparent and birefringent. The optical characteristics of the $\phi_{\mathrm{P}}=0.50$ sample were consistent with this expectation, while those of $\phi_{\mathrm{P}}=0.28$ and $\phi_{\mathrm{P}}=0.40$ were not. On the basis of the optical and SAXS experiments, we conclude that samples with $\phi_{\mathrm{P}}=0.28$ and $\phi_{\mathrm{P}}=0.40$ are a micellar phase with liquidlike local structure. In the case of cylinder phases, it has been shown that small grain sizes may prevent the observation of birefringence; ${ }^{46}$ 


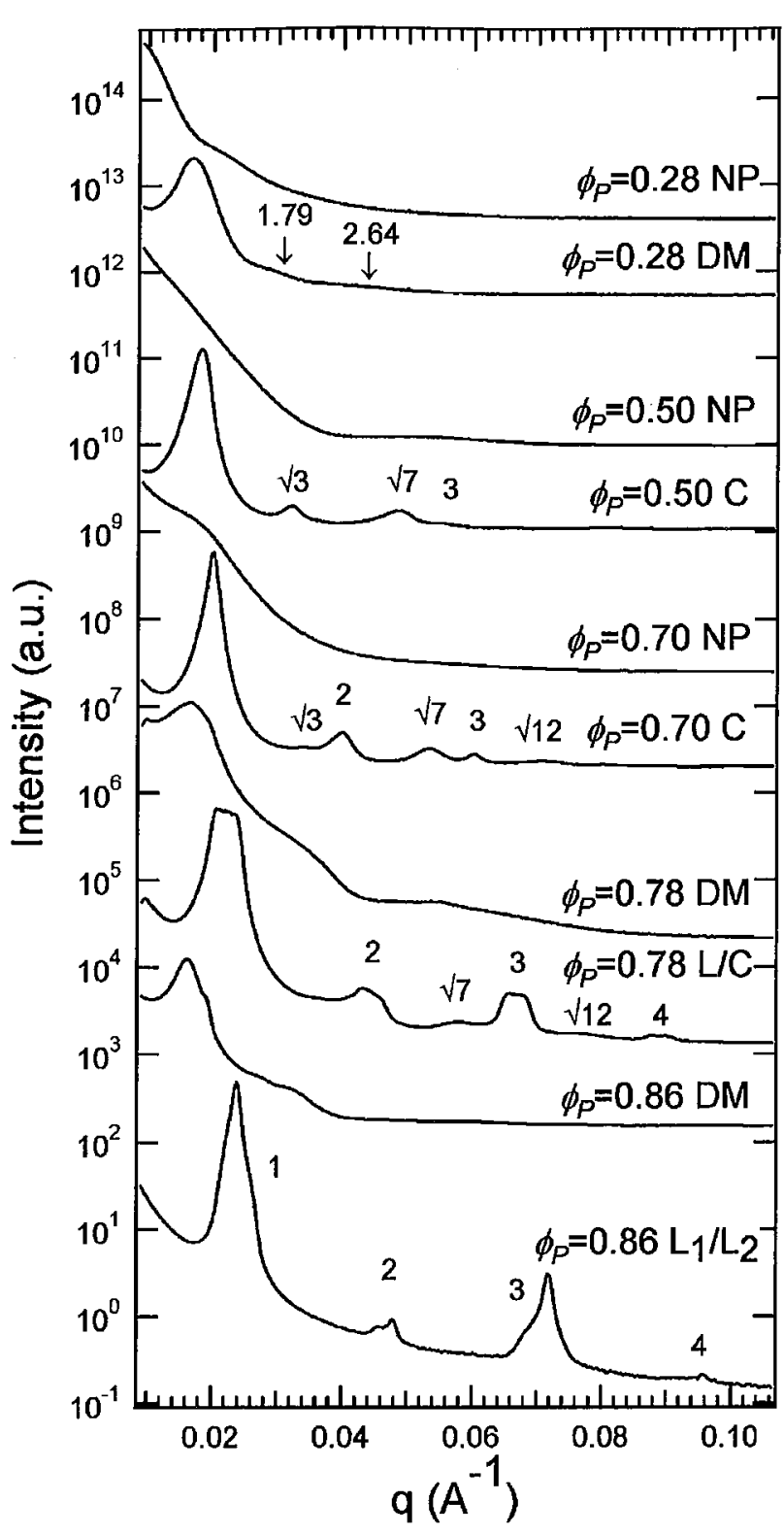

Figure 8. Comparison of ordered and disordered state SAXS scattering profiles (offset for clarity) for S2VP(13-15)/[Im][TFSI] mixtures at varying concentrations of block copolymer, $\phi_{\mathrm{P}}$. In all cases, the peak labels correspond to the $q / q^{*}$ for scattering peaks. For ordered state samples, $\mathrm{L}_{1} / \mathrm{L}_{2}$ corresponds to coexisting lamellae, $\mathrm{L} / \mathrm{C}$ corresponds to coexisting hexagonally packed cylinders and lamellae, $\mathrm{C}$ corresponds to cylinders, and DM corresponds to micelles with liquidlike local structure. In all cases, the ordered state SAXS profiles were obtained at $145^{\circ} \mathrm{C}$ and the disordered (DM) or nonperiodic disordered (NP) SAXS . profiles were obtained at $245^{\circ} \mathrm{C}$.

however, in the $\phi_{\mathrm{P}}=0.28$ and $\phi_{\mathbf{P}}=0.40$ samples we do not know the origin of the low optical transmission coefficient in the micellar samples. The transition from ordered microstructures to disordered micelles occurs at $\phi_{\mathrm{P}}=0.45 \pm 0.05$.

In related studies of block copolymer/ionic liquid mixtures, Simone and Lodge discovered the presence of disordered networked cylinders between lamellar and hexagonally packed cylinder regions of the phase diagram. ${ }^{14}$ The optical properties of the disordered network phase were not presented in ref 14 . Further work is needed to determine if the disordered phase observed in our system has a similar morphology or if it more
Table 1. Thermal Properties for Varying Compositions of S2VP(1315) Copolymer in [Im||TFSI]

\begin{tabular}{llccl}
\hline$\phi_{\mathrm{P}}$ & $T_{\mathrm{g}}\left({ }^{\circ} \mathrm{C}\right)^{a}$ & $T_{\mathrm{c}}\left({ }^{\circ} \mathrm{C}\right)^{a}$ & $T_{\mathrm{m}}\left({ }^{\circ} \mathrm{C}\right)^{a}$ & $T_{\mathrm{d}}\left({ }^{\circ} \mathrm{C}\right)^{b}$ \\
\hline 1.0 & 94 & - & - & 378 \\
0.99 & 101 & - & - & 370 \\
0.97 & 99 & - & - & 332 \\
0.93 & 95,120 & - & - & not measured \\
0.78 & 58,95 & - & - & not measured \\
0.70 & 40 & - & 69 & not measured \\
0.50 & $-4,47-95$ & - & - & 327 \\
0.40 & - & 24 & 51 & not measured \\
0.0 & - & - & 74 & not measured
\end{tabular}

"Onset temperatures of heat capacity change (glass transition temperature, $T_{\mathrm{g}}$ ), an exotherm peak (crystallization temperature, $T_{\mathrm{c}}$ ), and an endotherm peak (melting temperature, $T_{\mathrm{m}}$ ) during heating scan using differential scanning calorimetry. ${ }^{b}$ Temperature of $10 \%$ weight loss heating scan from room temperature using thermal gravimetric analysis.

closely related to spherical micelles with liquidlike local structure observed in diblock copolymer melts. ${ }^{46-48}$

Both experimental ${ }^{49}$ and theoretical ${ }^{18}$ studies have previously shown that the addition of nonselective solvents leads to a decrease in $d$ due to screening of unfavorable interactions between the two block copolymer segments. In the case of selective solvents, Banaszak and Whitmore ${ }^{50}$ used self-consistent mean-field theory (SCFT) to show that addition of a selective solvent results in an increase in $d$ due to changes in the configuration of the polymer chains as they minimize unfavorable thermodynamic interactions between the selective solvent and the block copolymer segment with poor solubility in the solvent. The domain spacing of a block copolymer swollen with a selective solvent has been shown experimentally ${ }^{18,21}$ and theoretically ${ }^{18}$ to follow the power law

$$
d \sim \phi_{\mathrm{P}}^{\alpha}
$$

where $\alpha$ depends on solvent - polymer interactions and interfacial curvature. In Figure 4, we plot $q^{*}$, the SAXS domain spacing from the primary 100 scattering peak of lamellar S2VP(13-15)/ [Im][TFSI] mixtures, versus $\phi_{\mathrm{P}}\left(0.93 \leq \phi_{\mathbf{P}} \leq 1.0\right)$. We observe $\alpha$ values of -2.31 and -3.16 at temperatures of 145 and $225^{\circ} \mathrm{C}$, respectively. The negative values of $\alpha$ are not surprising as it demonstrates selectivity of the [Im][TFSI] ionic liquid solvent toward one segment of the S2VP(13-15) copolymer, which we believe to be the P2VP block. Our finding is in qualitative agreement with the selective solvent domain scaling behavior observed by Simone and Lodge using a PB-block-PEO copolymer in imidazolium ionic liquids. ${ }^{14}$ Previous studies on the effect of temperature on solvent selectivity for molecular solvents such as water ${ }^{24,25}$ and high boiling point organics ${ }^{15,18}$ have obtained $\alpha$ values that are sensitive functions of temperature due to the temperature dependencies of the underlying thermodynamic factors. This appears to also be true for the S2VP(13-15)/[Im][TFSI] system. On the basis of the temperature dependence of $\alpha$, SCFT of mixtures of block copolymers and selective molecular solvents, and this limited data set, we are led to the conclusion that the selectivity of [Im][TFSI] toward the P2VP block increases with increasing temperature.

The temperature dependence of $q^{*}$ for $\operatorname{S} 2 \mathrm{VP}(13-15) /[\mathrm{Im}]-$ [TFSI] mixtures over a wide concentration range is shown in Figure 5. At high S2VP(13-15) concentrations $\left(\phi_{\mathrm{P}} \geq 0.97\right), q^{*}$ increases with increasing temperature (Figure 5a). In this regime of low ionic liquid concentration, we expect the interactions between the PS and P2VP segments to dominate. This would lead to an increase in $q^{*}$ with increasing temperature due to a decrease of the Flory-Huggins interaction parameter

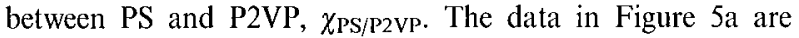
consistent with this expectation. While we believe that the 


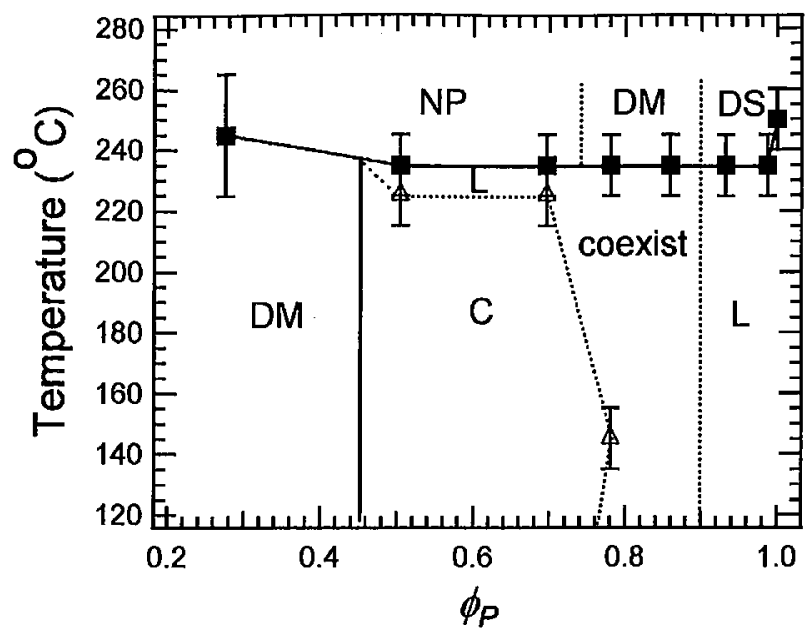

Figure 9. Phase diagram of S2VP(13-15)/[Im][TFSI] mixtures. Filled symbols (ם) indicate order-disorder transition temperatures, while open symbols $(\Delta)$ indicate order-order transitions observed using SAXS with indicated error bars. The solid line indicates the boundary between ordered and disordered (DS), disordered micelle with liquidlike local structure (DM), or nonperiodic disordered (NP) phases. The dashed lines indicate boundaries between lamellae (L) and hexagonally packed cylinders $(\mathrm{C})$ ordered phases and DS, DM, and NP disordered phases. A region of coexistence (coexist) is observed between $\mathrm{L}$ and $\mathrm{C}$ regions.

$\chi_{\mathrm{PS} / \mathrm{P} 2 \mathrm{VP}}$ interaction parameter dominates in this composition range, it is instructive to examine the temperature dependence of domain size in block copolymer/salt mixtures. In systems based on $\mathrm{LiClO}_{4}$ salts in triblock copolymers containing a PEO segment, small decreases in domain spacing upon heating were attributed to the physical cross-linking behavior of the salt, ${ }^{51}$ in agreement with results from the S2VP(13-15)/[Im][TFSI] system. At intermediate block copolymer concentrations $\left(0.40 \leq \phi_{\mathrm{P}} \leq 0.86\right)$, the domain spacing is nearly independent of temperature at low temperatures, while $q^{*}$ decreases rapidly at high temperatures as the samples approach the order-disorder transition (ODT) temperature (Figure 5a,b). For $\phi_{\mathrm{P}}=0.28$, the domain spacing is nearly independent of temperature. In contrast, both experiments and SCFT indicate that $q^{*}$ of block copolymers in selective molecular solvents increases with increasing temperature, regardless of polymer concentration. ${ }^{44,50}$ While we have not yet modeled interactions between ionic liquids and block copolymers, there is little doubt that substantial extension of the standard SCFT will be needed to describe the self-assembly of these systems.

In Figure 6a we show the temperature dependence of the SAXS profile of the $\phi_{\mathrm{P}}=0.99$ sample. At $145^{\circ} \mathrm{C}$, the sample exhibits a lamellar morphology, as seen by the $2 q^{*}$ and $3 q^{*}$ higher order scattering peaks. When the sample is heated to $235 \pm 10^{\circ} \mathrm{C}$, the higher order peaks disappear. This is one of the signatures of an order-disorder transition. ${ }^{52,53}$ Figure $6 \mathrm{~b}$ shows the dependence of the value of $I\left(q^{*}\right)$ and the fwhm of the primary SAXS peak versus temperature. The discontinuity in the value of $I\left(q^{*}\right)$ at $235 \pm 10{ }^{\circ} \mathrm{C}$ is a standard signature of an ODT, and we conclude that the $\phi_{\mathrm{P}}=0.99$ sample undergoes an ODT at $235 \pm 10^{\circ} \mathrm{C}$. An abrupt broadening of the primary scattering peak when the ordered phase gives way to the disordered phase is a typical signature of the ODT in neat block copolymers and block copolymers dissolved in molecular solvents. However, in the $\phi_{\mathrm{P}}=0.99$ sample, there is no abrupt change in fwhm at the ODT as seen in Figure $6 \mathrm{~b}$.

In Figure 7a, we plot the SAXS intensity versus $q$ from the $\phi_{\mathrm{P}}=0.70$ sample at selected temperatures above the $T_{\mathrm{g}}$ of the neat

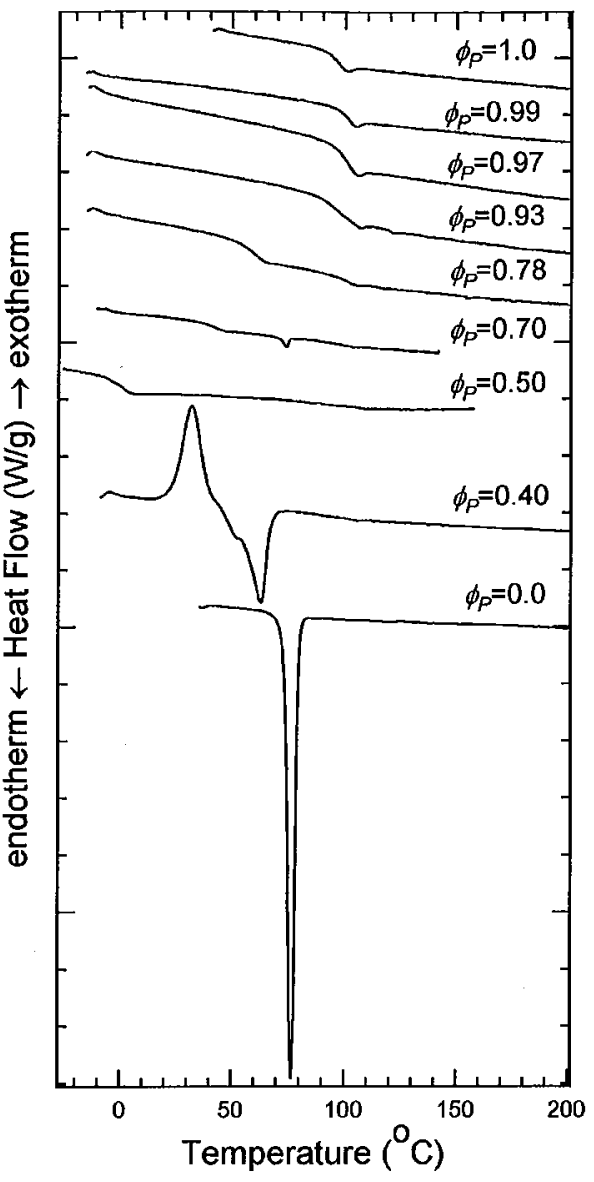

Figure 10. DSC thermograms (offset for clarity) of varying concentrations of S2VP(13-15) copolymer in [Im][TFSI]. The heating rate is $10^{\circ} \mathrm{C} / \mathrm{min}$.

block copolymer $\left(94{ }^{\circ} \mathrm{C}\right)$. At $145^{\circ} \mathrm{C}$, the sample exhibits a hexagonally packed cylinder morphology, as evidenced by the $\sqrt{ } 3 q^{*}, 2 q^{*}, \sqrt{ } 7 q^{*}$, and $3 q^{*}$ higher order scattering peaks. Samples annealed for $24 \mathrm{~h}$ at $145^{\circ} \mathrm{C}$ exhibit the same hexagonally packed cylinder morphology, indicating that this morphology is not dependent on processing history. This morphology persists upon heating until $225 \pm 10^{\circ} \mathrm{C}$ when an order-order transition (OOT) to a lamellar microstructure is observed, as evidenced by the disappearance of higher order scattering peaks corresponding to hexagonal symmetry and the persistence of the $2 q^{*}, 3 q^{*}$, and $4 q^{*}$ higher order scattering peaks. Upon heating to $235 \pm 10^{\circ} \mathrm{C}$, all higher order scattering peaks disappear and the primary peak broadens considerably. In Figure $7 \mathrm{~b}$, we show the temperature dependence of both the value of $I\left(q^{*}\right)$ and fwhm for the $\phi_{\mathrm{P}}=0.70$ sample. The SAXS signatures of this sample are consistent with those obtained in neat block copolymers and their mixtures with molecular solvents at the ODT; i.e., the higher order peaks disappear, and the fwhm of the primary peak increases abruptly as the ODT is crossed. ${ }^{52,54,55}$ In contrast, crossing the cylinder-to-lamellae transition results in an increase in $I\left(q^{*}\right)$ and a decrease in fwhm. Sequential cylinder-to-lamellaeto-disorder transitions have been seen previously in mixtures of block copolymers and selective molecular solvents wherein the selectivity of the solvent decreases with increasing temperature. ${ }^{18}$ However, the data in Figure 4 suggest that in the S2VP(13-15)/ [Im][TFSI] system the selectivity of [Im][TFSI] toward the P2VP block increases with increasing temperature.

For values of $\phi_{\mathbf{P}} \geq 0.93$, the ODT is reversible; i.e., cooling the sample below the ODT temperature after disordering results 

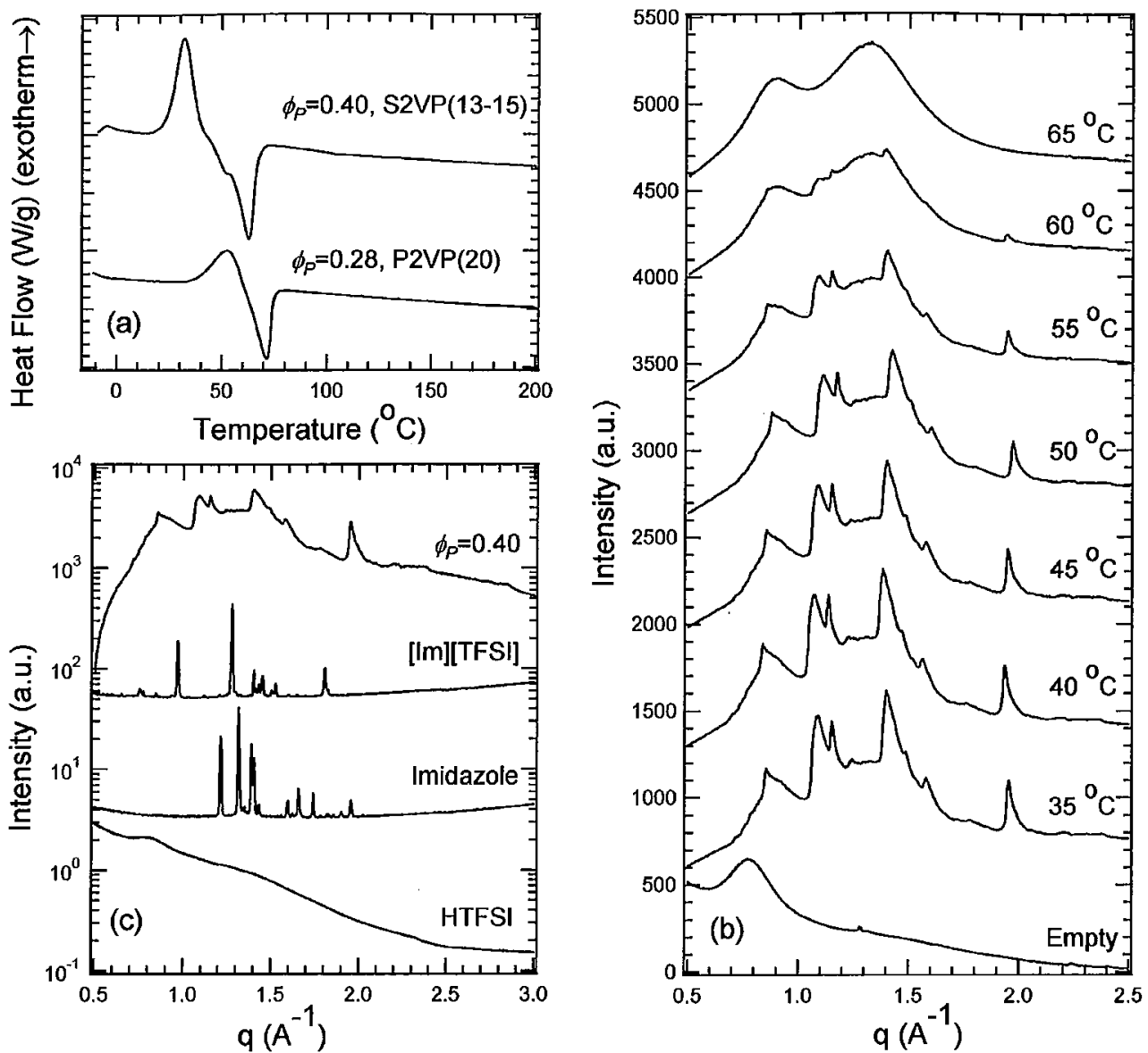

Figure 11. (a) DSC thermograms (offset for clarity) of $\phi_{\mathrm{P}}=0.40$ in $\mathrm{S} 2 \mathrm{VP}(13-15)$ copolymer and $\phi_{\mathrm{P}}=0.28$ in $\mathrm{P} 2 \mathrm{VP}(20)$ at a $10^{\circ} \mathrm{C} / \mathrm{min}$ scan rate. (b) WAXS intensity profiles (offset for clarity) of $\phi_{\mathrm{P}}=0.40 \mathrm{in} \mathrm{S2VP}(13-15)$ copolymer at varying temperatures and empty Kapton cell. The features at $q=0.85 \mathrm{~A}^{-1}$ are an artifact of the empty cell subtraction. (c) WAXS intensity profiles (offset for clarity) of $\phi_{\mathbf{P}}=0.40$ in S2VP(13-15) copolymer, neat [Im][TFSI], neat imidazole, and neat HTFSI at room temperature.

in the reformation of the ordered phase, and the data from this composition range are not shown. In the $\phi_{\mathbf{P}}=1.00$ and $\phi_{\mathbf{P}}=0.93$ samples, the ODT is characterized by the disappearance of higher order scattering peaks, a discontinuity in the value of $I\left(q^{*}\right)$, and an abrupt increase in the fwhm of the primary peak revealing phase mixing in the disordered state, consistent with ODT behavior in block copolymer melts and solutions in molecular solvents. In the $\phi_{\mathrm{P}}=0.99$ sample and $\phi_{\mathrm{P}}=0.97$ sample (data not shown), the disappearance of higher order scattering peaks and a discontinuity in the value of $I\left(q^{*}\right)$ is interpreted to be an ODT (Figure 7). While the disordered state in the range of $0.99 \geq \phi_{\mathrm{P}} \geq 0.97$ lacks long-range orientational order, the narrow width of the $I\left(q^{*}\right)$ peaks leads to speculation that the presence of small amounts of ionic liquid enforces local phase separation of PS and P2VP domains.

In contrast to the $\phi_{\mathrm{P}} \geq 0.93$ samples, none of the samples* with $\phi_{\mathrm{P}} \leq 0.86$ exhibit reversible ODTs. Cooling the sample below the ODT temperature after disordering does not result in the reformation of the ordered phase in spite of annealing the samples in the ordered state for $1 \mathrm{~h}$ at $145^{\circ} \mathrm{C}$. In Figure 8 we compare SAXS profiles obtained above and below the ODT for these samples. The SAXS profiles obtained from the disordered state at $\phi_{\mathrm{P}}=0.86$ and $\phi_{\mathrm{P}}=0.78$ contain broad shoulders in addition to the primary peak, suggesting the presence of a micellar phase with liquidlike local structure rather than a fluctuating disordered phase. It is conceivable that the formation of complex ordered phases from such micellar phases requires annealing times that are much longer than those used in this study. The presence of significant low angle scattering $\left(q<0.03 \AA^{-1}\right)$ in the disordered phase for samples with $\phi_{\mathbf{P}} \leq 0.70$ indicates the formation of nonperiodic, large length scale structures. These structures do not re-form ordered structures on experimental time scales after the samples are cooled below the ODT temperature. The fact that we were able to observe reversible phase transitions at low ionic liquid concentrations $\left(\phi_{\mathbf{P}} \geq 0.93\right)$ in the same temperature window suggests that thermal degradation does not play a role in these unusual transitions. In addition, we find that the molecular weight distribution as characterized by GPC of the neat block copolymer sample does not change after heating to $250^{\circ} \mathrm{C}$ for $24 \mathrm{~h}$ under vacuum. We were unable to make related GPC measurements of the block copolymer/ionic liquid mixtures after heating to $250{ }^{\circ} \mathrm{C}$, as HTFSI is a superacid and would cause irreparable damage the GPC columns. We also conducted TGA experiments on S2VP(13-15)/[Im][TFSI] mixtures and found that the temperatures at which a weight loss of $10 \%$ was observed was well above $300^{\circ} \mathrm{C}$ (Table 1 ).

In Figure 9, we present the phase diagram of S2VP(13-15)/ [Im][TFSI] mixtures. The measured ODTs and OOTs are indicated with markers, while lines are drawn to indicate interpolated phase boundaries. We limit our attention to temperatures above the glass transition temperature of the neat block copolymer $\left(94^{\circ} \mathrm{C}\right)$. At high S2VP(13-15) copolymer concentrations $\left(\phi_{\mathrm{P}} \geq 0.93\right)$, lamellae are observed at temperatures well above $T_{\mathrm{g}}$. Upon heating above $235 \pm 10^{\circ} \mathrm{C}$, samples in the high copolymer concentration range $\left(\phi_{\mathrm{P}} \geq 0.93\right)$ undergo a reversible 
ODT. As the concentration of block copolymer is decreased to $\phi_{\mathrm{P}}=0.86$ and $\phi_{\mathrm{P}}=0.78$, coexisting phases are obtained. These systems exhibit an irreversible ODT at $235 \pm 10^{\circ} \mathrm{C}$ to a disordered micelle morphology with liquidlike order. We note that the $\dot{\phi}_{\mathrm{P}}=0.86$ sample exhibits a coexisting lamellar phase, which we believe is a nonequilibrium phase due to small quench depth. Thus, the width with respect to $\phi_{\mathrm{P}}$ of this coexisting region may in fact be narrower at infinite equilibration times. The $\phi_{\mathrm{P}}=0.70$ and $\phi_{\mathbf{P}}=0.50$ samples form hexagonally packed cylinders at low temperatures and exhibit an OOT from hexagonally packed cylinders to lamellae at $225 \pm 10^{\circ} \mathrm{C}$. This transition was not reversible upon cooling to $215^{\circ} \mathrm{C}$ for $30 \mathrm{~min}$ and indicates that longer annealing times may be required to reform hexagonally packed cylinders. Upon heating the $\phi_{\mathrm{P}}=0.70$ and $\phi_{\mathbf{P}}=0.50$ samples to $235 \pm 10^{\circ} \mathrm{C}$ an irreversible ODT is observed. As the concentration of block copolymer is further reduced to $\phi_{\mathrm{P}}=0.40$, a lyotropic phase transition to a micellar morphology with liquidlike order is observed. This morphology persists at a block copolymer concentration of $\phi_{\mathbf{P}}=0.28$. Upon heating the $\phi_{\mathbf{P}}=0.28$ sample to $245 \pm 20^{\circ} \mathrm{C}$, an irreversible phase transition to a nonperiodic disordered phase is obtained.

The thermal properties of S2VP(13-15)/[Im][TFSI] mixtures were obtained from DSC heating scans at $10^{\circ} \mathrm{C} / \mathrm{min}$, the results are given in Figure 10, and the observed thermal transitions are summarized in Table 1. Both PS and P2VP homopolymers are known to undergo a glass transition in the vicinity of $100-105^{\circ} \mathrm{C}$ in the high molecular weight limit. ${ }^{56}$ It is thus not surprising that S2VP(13-15) exhibits a single glass transition temperature of $94^{\circ} \mathrm{C}$. On the other hand, pure [Im][TFSI] exhibits a melting transition at $74^{\circ} \mathrm{C}$ (Figure 10). It would be reasonable to expect the block copolymer/ionic liquid mixtures to exhibit a combination of the phase transitions seen in the pure components. It is thus not surprising that mixtures with $\phi_{\mathrm{P}} \geq 0.97$ exhibit a single glass transition with $T_{\mathrm{g}}$ values in the vicinity of $100^{\circ} \mathrm{C}$. It is interesting to note that the $T_{\mathrm{g}}$ values obtained from S2VP (13-15)/[Im][TFSI] mixtures are slightly higher than that of the neat S2VP(13-15) copolymer (Table 1). Salt ions are known to induce physical cross-links in polymer matrices, which in turn lead to an increase in $T_{\mathrm{g}}$, e.g., $\mathrm{LiClO}_{4} / \mathrm{PEO}$ electrolytes. ${ }^{35}$ The $\phi_{\mathrm{P}}=0.93$ sample exhibits two $T_{\mathrm{g}}$ 's at 95 and $120^{\circ} \mathrm{C}$. The phase with the high $T_{\mathrm{g}}$ is likely the P2VP-rich microphase, in which most of the [Im][TFSI] is expected to reside. The $\phi_{\mathbf{P}}=0.78$ sample exhibits two well-separated $T_{\mathrm{g}}$ 's at 58 and $95^{\circ} \mathrm{C}$. It appears that at this relatively high [Im][TFSI] concentration the plasticization effect due to the presence of the low molecular weight ionic liquid overwhelms the increase in $T_{\mathrm{g}}$ due to the presence of the physical cross-links. The $\phi_{\mathrm{P}}=0.70$ sample exhibits a glass transition at $40{ }^{\circ} \mathrm{C}$ corresponding to a plasticized P2VP microphase and a melting transition at $69^{\circ} \mathrm{C}$. This suggests the existence of pools of nearly pure [Im][TFSI] that probably reside within the P2VP phase. The $\phi_{\mathrm{P}}=0.50$ sample exhibits a sharp $T_{\mathrm{g}}$ at $-4^{\circ} \mathrm{C}$, and a broad $T_{\mathrm{g}}$ between 47 and $95^{\circ} \mathrm{C}$, corresponding to plasticization of the $\mathbf{P} 2 \mathrm{VP}$ and PS microphases, respectively. The $\phi_{\mathrm{P}}=0.40$ mixture exhibits interesting behavior that is not seen in either of the pure components. Heating the $\phi_{\mathrm{P}}=0.40$ sample first results in a prominent. crystallization peak $\left(T_{\mathrm{c}}=24{ }^{\circ} \mathrm{C}\right)$ followed by a melting peak $\left(T_{\mathrm{m}}=51^{\circ} \mathrm{C}\right)$. This sequence of phase transitions is typically seen in nonstoichiometric [Im][TFSI] systems (salt in ionic liquid), in which a homogeneous liquid is formed, while phase separation occurs in the solid state. ${ }^{4}$ However, we have added stoichiometric amounts of imidazole and HTFSI to the block copolymer.

We propose that specific $\mathrm{P} 2 \mathrm{VP} /$ ionic liquid interactions lead to this unusual sequence of phase transitions. In Figure 1 la we show DSC thermograms from the $\phi_{\mathrm{P}}=0.40$ in $\mathrm{S} 2 \mathrm{VP}$ copolymer and a $\phi_{\mathbf{P}}=0.28$ sample in $\mathrm{P} 2 \mathrm{VP}(20)$ homopolymer at a $10^{\circ} \mathrm{C} / \mathrm{min}$ scan rate. Both samples exhibit a qualitatively similar crystallization transition followed by melting transition, demonstrating that crystallization induced by microphase separation of the block copolymer does not play a role in this unusual transition. The enthalpy associated with these thermal transitions was found to be independent of scan rate. Vinylpyridine/imidazole interactions or intermolecular imidazole interactions induced by the P2VPenvironment appear to enable this transition. The $T_{\mathrm{m}}$ in the $\phi_{\mathrm{P}}=0.40 \mathrm{~S} 2 \mathrm{VP}$ copolymer sample was confirmed with wideangle X-ray scattering (WAXS) and is shown in Figure $11 \mathrm{~b}$. In addition, the structure of the [Im][TFSI] ionic liquid, neat imidazole, and neat HTFSI were characterized with WAXS and are shown in Figure 11c. The diffraction peak at $q=1.95 \mathrm{~A}^{-1}$ present in the $\phi_{\mathrm{P}}=0.40 \mathrm{~S} 2 \mathrm{VP}$ copolymer and neat imidazole sample coincides with intermolecular interactions present in crystalline imidazole. ${ }^{57}$ While this suggests the presence of imidazole-rich phases within the $\phi_{\mathrm{P}}=0.40 \mathrm{~S} 2 \mathrm{VP}$ copolymer sample, additional vinylpyridine/imidazole or vinylpyridine/ ionic liquid interactions appear to give rise to the complex scattering profile observed in the $\phi_{\mathrm{P}}=0.40 \mathrm{~S} 2 \mathrm{VP} /[\mathrm{Im}][\mathrm{TFSI}]$ mixture, and we have not determined the nature of the crystals therein.

\section{Conclusions}

We have examined the lyotropic and thermotropic phase behavior of a S2VP copolymer in [Im][TFSI] using SAXS and optical transmission characterization. We established that the ionic liquid selectively solvates one of the block copolymer segments, which we believe to be the P2VP domain. The SAXS data indicated the existence of lamellar, cylindrical, and disordered phases. Some of the signatures of order-order and orderdisorder transitions in S2VP/[Im][TFSI] mixtures differ from those found in mixtures of block copolymers and molecular solvents. The thermal properties of the system provide interesting insight into the nature of the self-assembled microdomains. At high block copolymer concentrations $\left(\phi_{\mathrm{P}} \geq 0.93\right.$ ), the ionic liquid behaves as a salt, causing a slight increase in the $T_{\mathrm{g}}$ of P2VP domains, while at intermediate block copolymer concentrations $\left(0.50 \leq \phi_{\mathrm{P}} \leq 0.78\right)$ the ionic liquid behaves as a plasticizer, causing a decrease in the $T_{\mathrm{g}}$ of P2VP domains. At $\phi_{\mathrm{P}}=0.40$ an unusual thermal transition consisting of crystallization and subsequent melting is observed and is attributed to specific P2VP/[Im][TFSI] interactions.

Acknowledgment. We gratefully acknowledge support from the Department of Energy, Office of Basic Energy Sciences, under Contract DE-AC02-05CH11231. The authors thank Dr. John Kerr and Dr. Leanne Beer for experimental assistance and use of a glovebox for sample preparation and Professor Alex Katz and Jarred Ghilarducci for use of a TGA instrument. SAXS and WAXS experiments were performed at the Advanced Light Source and the Stanford Synchrotron Radiation Laboratory. Both are national user facilities supported by the Department of Energy, Office of Basic Energy Sciences. We gratefully acknowledge Eliot Gann for experimental assistance at the ALS and Tom Hostetler for experimental assistance at the SSRL.

\section{References and Notes}

(1) Wassercheid, P.; Welton, T. Ionic Liquids in Synthesis; Wiley-VCH Verlag: Weinheim, 2003.

(2) Sakaebe, H.; Matsumoto, H. Electrochem. Commun. 2003, 5 (7), 594-598.

(3) Kim, G. T.; Appetecchi, G. B.; Alessandrini, F.; Passerini, S. J. Power Sources 2007, I7I (2), 861-869.

(4) Noda, A.; Susan, A. B.; Kudo, K.; Mitsushima, S.; Hayamizu, K.; Watanabe, M. J. Phys. Chem. B 2003, 107 (17), 4024-4033.

(5) Matsuoka, H.; Nakamoto, H.; Susan, M.; Watanabe, M. Electrochim. Acia 2005, 50 (19), 4015-4021.

(6) Fernicola, A.; Panero, S.; Scrosati, B.; Tamada, M.; Ohno, H. ChemPhysChem 2007, 8 (7), 1103-1107. 
(7) Sekhon, S. S.; Lalia, B. S.; Park, J. S.; Kim, C. S.; Yamada, K. J. Mater. Chem. 2006, 16 (23), 2256-2265.

(8) Doyle, M.; Choi, S. K.; Proulx, G. J. Electrochem. Soc. 2000, 147 (1), $34-37$.

(9) Kawano, R.; Matsui, H.; Matsuyama, C.; Sato, A.; Susan, M.; Tanabe, N.; Watanabe, M. J. Photochem. Photobiol., A 2004, 164 $(1-3), 87-92$.

(10) Stathatos, E.; Lianos, R.; Zakeeruddin, S. M.; Liska, P.; Gratzel, M. Chem. Mater. 2003, 15 (9), 1825-1829.

(11) Wang, M.; Xiao, X. R.;Zhou, X. W.; Li, X. P.; Lin, Y. Sol. Energy Mater. Sol. Cells 2007, 91 (9), 785-790.

(12) Yamanaka, N.; Kawano, R.; Kubo, W.; Masaki, N.; Kitamura, T.; Wada, Y.; Watanabe, M.; Yanagida, S. J. Phys. Chem. B 2007, 11I (18), 4763-4769.

(13) Susan, M. A.; Kaneko, T.; Noda, A.; Watanabe, M. J. Am. Chem. Soc. 2005, $127(13), 4976-4983$.

(14) Simone, P. M.; Lodge, T. P. Macromolecules 2008, 41, 1753-1759.

(15) Lai, C. J.; Russel, W. B.; Register, R. A. Macromolecules 2002, 35 (3), 841-849.

(16) Lodge, T. P.; Pudil, B.; Hanley, K. J. Macromolecules 2002, 35 (12), $4707-4717$.

(17) Lodge, T. P.; Hanley, K. J.; Pudil, B.; Alahapperuma, V. Macromolecules 2003, 36 (3), 816-822.

(18) Hanley, K. J.; Lodge, T. P.; Huang, C. I. Macromolecules 2000, 33 (16), 5918-5931

(19) Huang, C. I.; Lodge, T. P. Macromolecules 1998, 31 (11), 3556-3565.

(20) Whitmore, M. D.; Noolandi, J. J. Chem. Phys. 1990, 93(4), 2946-2955.

(21) Lai, C. J.; Russel, W. B.; Register, R. A. Macromolecules 2002, 35 (10), 40444049

(22) Alexandridis, P.; Holzwarth, J. F.; Hatton, T. A. Macromolecules 1994, 27 (9), 2414-2425.

(23) Alexandridis, P.; Nivaggioli, T.; Hatton, T. A. Langmuir 1995, 11 (5), 1468-1476.

(24) Hajduk, D. A.; Kossuth, M. B.; Hillmyer, M. A.; Bates, F. S. J. Phys. Chem. B 1998, 102 (22), 4269-4276.

(25) Malcolm, G. N.; Rowlinson, J. S. Trans. Faraday Soc. 1957, 53(7), 921-931.

(26) Rikukawa, M.; Sanui, K. Prog. Polym. Sci. 2000, 25 (10), 1463-1502.

(27) Smitha, B.; Sridhar, S.; Khan, A. A. J. Membr. Sci. 2005, $259(1-2)$, $10-26$.

(28) Park, M. J.; Downing, K. H.; Jackson, A.; Gomez, E. D.; Minor, A. M.; Cookson, D.; Weber, A. Z.; Balsara, N. P. Nano Lett. 2007, 7 (11), 3547-3552.

(29) Kim, J.; Kim, B.; Jung, B. J. Membr. Sci. 2002, 207 (1), 129-137.

(30) Yang, C.; Costamagna, P.; Srinivasan, S.; Benziger, J.; Bocarsly, A. B. J. Power Sources 2001, 103 (1), 1-9.

(31) Kreuer, K. D.; Paddison, S. J.; Spohr, E.; Schuster, M. Chem. Rev. 2004, 104 (10), 4637-4678.

(32) Ohno, H.; Yoshizawa, M.; Ogihara, W. Electrochim. Acta 2004, 50 (2-3), 255-261.

(33) Yoshio, M.; Kagata, T.; Hoshino, K.; Mukai, T.; Ohno, H.; Kato, T. J. Am. Chem. Soc. 2006, 128 (16), 5570-5577.
(34) He, Y. Y.; Boswell, P. G.; Buhlmann, P.; Lodge, T. P. J. Phys. Chem. B 2007, 111 (18), 4645-4652.

(35) Wise, D. L.; Wnek, G. E.; Trantolo, D. J.; Cooper, T. M.; Gresser, J. D. Electrical and Optical Polymer Systems: Fundamentals: Methods, and Applications; Marcel Dekker: New York, 1998.

(36) Khan, I. M.; Fish, D.; Delaviz, Y.; Smid, J. Makromol. Chem. 1989, $190(5), 1069-1078$.

(37) Klingshirn, M. A.; Spear, S. K.; Subramanian, R.; Holbrey, J. D.; Huddleston, J. G.; Rogers, R. D. Chem. Mater. 2004, 16 (16), 3091-3097.

(38) Schulz, M. F.; Khandpur, A. K.; Bates, F. S.; Almdal, K.; Mortensen, K:; Hajduk, D. A.; Gruner, S. M. Macromolecules 1996, 29 (8), 2857-2867.

(39) Virgili, J. M.; Nedoma, A. J.; Melnichenko, Y. B.; Cheng, G.; Balsara, N. P.; Segalman, R. A. Abstracts of Papers of the American Chemical Society, 2009, in press.

(40) Garetz, B. A.; Newstein, M. C.; Dai, H. J.; Jonnalagadda, S. V.; Balsara, N. P. Macromolecules 1993, 26 (12), 3151-3155.

(41) Hamley, I. W. The Physics of Block Copolymers; Oxford University Press: New York, 1998.

(42) Laughlin, R. G. The Aqueous Phase Behavior of Surfactants; Academic Press: San Diego, 1994.

(43) Hajduk, D. A.; Takenouchi, H.; Hillmyer, M. A.; Bates, F. S.; Vigild, M.E.; Almdal, K. Macromolecules 1997, 30(13), 3788-3795.

(44) Hanley, K. J.; Lodge, T. P. J. Polym. Sci., Part B: Polym. Phys. 1998, $36(17), 3101-3113$.

(45) Jain, S. M.; Gong, X. B.; Scriven, L. E.; Bates, F. S. Phys, Rev. Lett. 2006, 96 (13), 138304.

(46) Abuzaina, F. M.; Patel, A. J.; Mochrie, S.; Narayanan, S.; Sandy, A.; Garetz, B. A.; Balsara, N. P. Macromolecules 2005, 38 (16), 7090-7097.

(47) Semenov, A. N. Macromolecules 1989, 22 (6), 2849-2851.

(48) Dormidontova, E. E.; Lodge, T. P. Macromolecules 2001, 34 (26), 9143-9155.

(49) Hashimoto, T.; Shibayama, M.; Kawai, H. Macromolecules 1983, $16(7), 1093-1101$.

(50) Banaszak, M.; Whitmore, M. D. Macromolecules 1992, 25 (13), 3406-34I2.

(51) Epps, T. H.; Bailey, T. S.; Waletzko, R.; Bates, F. S. Macromolecules 2003, $36(8), 2873-2881$

(52) Sakamoto, N.; Hashimoto, T. Macromolecules 1995, $28(20), 6825-$ 6834

(53) Hahn, H.; Chakraborty, A. K.; Das, J.; Pople, J. A.; Balsara, N. P. Macromolecules 2005, 38 (4), 1277-1285.

(54) Bates, F. S.; Rosedale, J. H.; Fredrickson, G. H. J. Chem. Phys. $1990,92(10), 6255-6270$

(55) Lodge, T. P.; Xu, X.; Ryu, C. Y.; Hamley, I. W.; Fairclough, J. P. A.; Ryan, A. J.; Pedersen, J.S. Macromolecules 1996, 29 (18), 5955-5964.

(56) Peyser, P. In Glass Transition Temperatures of Polymers. In Polymer Handbook, 3rd ed.; Brandrup, J., Immergut, E. H., Eds.; John Wiley and Sons: New York, 1989; p VI 209.

(57) Martinez, S. Acta Crystallogr. 1966, 20, 783-789. 


\section{DISCLAIMER}

This document was prepared as an account of work sponsored by the United States Government. While this document is believed to contain correct information, neither the United States Government nor any agency thereof, nor the Regents of the University of California, nor any of their employees, makes any warranty, express or implied, or assumes any legal responsibility for the accuracy, completeness, or usefulness of any information, apparatus, product, or process disclosed, or represents that its use would not infringe privately owned rights. Reference herein to any specific commercial product, process, or service by its trade name, trademark, manufacturer, or otherwise, does not necessarily constitute or imply its endorsement, recommendation, or favoring by the United States Government or any agency thereof, or the Regents of the University of California. The views and opinions of authors expressed herein do not necessarily state or reflect those of the United States Government or any agency thereof or the Regents of the University of California. 